\title{
Droplet and fibril formation of the functional amyloid Orb2
}

\author{
Kidist Ashami ${ }^{\mathrm{a}}$, Alexander S. Falk ${ }^{\mathrm{a}, 1}$, Connor Hurd ${ }^{\mathrm{a}}$, Samridhi Garga, ${ }^{\mathrm{a}}$, Silvia A. Cervantes ${ }^{\mathrm{a}}$, \\ Anoop Rawat ${ }^{\mathrm{a}}$, Ansgar B Siemer ${ }^{\mathrm{a}, *}$ \\ ${ }^{a}$ Department of Physiology and Neuroscience, Zilkha Neurogenetic Institute, Keck School of Medicine, \\ University of Southern California, 1501 San Pablo Street, CA 90033, Los Angeles, USA
}

\begin{abstract}
The functional amyloid Orb2 belongs to the cytoplasmic polyadenylation element binding (CPEB) protein family and plays an important role in long-term memory formation in Drosophila. The Orb2 domain structure combines RNA recognition motifs with low complexity sequences similar to many RNA binding proteins shown to form protein droplets via liquid-liquid phase separation (LLPS) in vivo and in vitro. This similarity suggests that Orb2 might also undergo LLPS. However, cellular Orb2 puncta have very little internal protein mobility and Orb2 forms fibrils in Drosophila brains that are functionally active indicating that LLPS might not play a role for Orb2. In the present work, we reconcile these two views on Orb2 droplet formation. We show that soluble Orb2 can indeed phase separate into protein droplets. However, these droplets have either no or only an extremely short-lived liquid phase and appear maturated right after formation. For Orb2 fragments that lack the C-terminal RNA binding domain (RBD), droplet formation is a prerequisite for fibril formation of an otherwise stable monomeric Orb2 solution. Solid-state NMR shows that these fibrils have additional well ordered static domains beside the Gln/His-rich fibril core. Further, we find that full-length Orb2B, which is by far the major component of Orb2 fibrils in vivo, does not transition into cross- $\beta$ fibrils but remains in the droplet phase. Together, our data suggest that phase separation might play a role in initiating the formation of functional Orb2 fibrils.
\end{abstract}

\section{Introduction}

Orb2 is a cytoplasmic polyadenylation element binding (CPEB) protein that can form functional cross- $\beta$ (amyloid) fibrils with a regulatory role for long-term memory (LTM) formation in Drosophila [1]. In its monomeric form, it promotes the deadenlyation of target messenger mRNA. When aggregating into cross- $\beta$ fibrils, it becomes an activator of the polyadenlya-

\footnotetext{
${ }^{*}$ Corresponding author

Email address: asiemer@usc.edu (Ansgar B Siemer)

${ }^{1}$ Present address: Kite Pharma, Emeryville, California, USA

${ }^{2}$ Present address: Department of Biochemistry, University of Wisconsin-Madison, USA
} 
tion and thereby the translation of mRNAs resulting in a stabilization of memories past 48 h [2, 3, 4, [5. Orb2 has two isoforms, Orb2A and Orb2B, which both share two C-terminal RNA recognition motifs (RRMs), a C-terminal zinc finger, a central Gly-rich region, and a Gln/His-rich domain that forms the core of Orb2 fibrils (see Figure 1) 2, 6].

In vivo, Orb2A is of relatively low abundance and only increases in concentration upon synaptic stimulation [7]. However, its presence is essential for the aggregation of the common isoform Orb2B [3, 4]. Orb2A has 9 unique N-terminal residues that can form cross- $\beta$ fibrils on their own [8] and whose deletion or mutations prevents Orb2 aggregation and LTM formation 4]. The deletion of Orb2A's C-terminus has no phenotype [3, 9]. The N-terminus of Orb2B is Ser/Gly-rich and of unknown function. Hervás and co-workers recently determined the structure of the Orb2 fibril core, which located in the Gln/His-domain, using cryo-EM [].

The domain structure of Orb2 that combines low complexity sequences with RNA binding domains is reminiscent of a whole class of RNA binding proteins, such as FUS, that are able to undergo liquid-liquid phase separation (LLPS) 10, 11, 12. LLPS is often of functional relevance e.g. for RNA processing in the case of (stress) granules [13], or for neurotransmitter release and postsynaptic signal transmission in neurons [14, 15]. Additionally, other Gln-rich proteins such as huntingtin exon-1 $\left(\mathrm{HTT}_{\mathrm{ex} 1}\right)$ or Whi3 have been reported to undergo LLPS 16, 17. When observed via light microcopy, LLPS manifests as droplet or puncta formation. These droplets, while relatively fluid at first, can mature over time which results in the decreased ability to fuse with other droplets and low fluorescence recovery after photobleaching (FRAP) [18, 19]. Structurally, this maturation is caused by reduced protein diffusion in the droplet phase, which becomes a rigid protein glass. These mature droplets can in cases such as FUS mutants or $\mathrm{HTT}_{\text {ex1 }}$ be the nucleation point of cross- $\beta$ fibril formation [20, 16]. Taken together, these findings suggest that Orb2 could also undergo phase separation, which could have a potential role for its function, or its aggregation into cross- $\beta$ fibrils, or both. In the following, we answer the question of whether or not Orb2 can undergo phase separation by demonstrating that it indeed can. Further, we characterize droplet maturation and fibril formation of different Orb2 fragments to understand the relationship between Orb2 droplet and fibril formation.

\section{Results}

To determine if Orb2 can phase separate in vitro, we studied full length Orb2B, and Orb2A and Orb2B fragments without the C-terminal RNA binding domain (RBD), which we refer to as $\triangle \mathrm{RBD}$ constructs (Figure 1). We did not study full-length Orb2A because it does not require its RBD for proper function in vivo [3] and because we were not able to make it in large quantities. To test if Orb2 can undergo phase separation, we started in conditions that 
favored a stable monomeric state, namely $100 \mathrm{mM} \mathrm{KCl}, 1 \mathrm{M}$ urea, $10 \mathrm{mM}$ HEPES, 0.05\% v/v $\beta$-mercaptoethanol, $\mathrm{pH}$ 7.6, here referred to as HEPES-salt-urea buffer (HSU Buffer). When left in HSU-buffer, Orb2 monomers did phase separate or form aggregates.

To introduce droplet formation, we exchanged each Orb2 construct from HSU buffer into H-Buffer (10 mM HEPES, $0.03 \% \mathrm{v} / \mathrm{v} \mathrm{NaN} 3$ and $0.05 \% \mathrm{v} / \mathrm{v} \beta$-mercaptoethanol, $\mathrm{pH} 6.5)$. Immediately upon exchange, the solutions became visibly turbid (Figure $2 \mathrm{~A}$ ). To further confirm that Orb2B, Orb2B $\triangle \mathrm{RBD}$, and Orb2A $\triangle \mathrm{RBD}$ underwent droplet formation, we used differential interference contrast (DIC) and fluorescence microscopy of Oregon Green 488 labeled protein (Figure 2B). Round protein droplets were visible for all constructs immediately after buffer exchange. The average diameters of Orb2B $\triangle \mathrm{RBD}$, Orb2A $\triangle \mathrm{RBD}$, and Orb2B droplets were $1.3 \pm 1.0 \mu \mathrm{m}, 2.2 \pm 1.1 \mu \mathrm{m}$, and $1.8 \pm 1.4 \mu \mathrm{m}$, respectively (see Figure S1). Morphological analysis 21] showed that the droplets had a high degree of roundness of 0.7-0.9. Besides H-buffer (i.e. low ionic strength), we found that both 10\% PEG 8000 and polyA at a 1:10 RNA:protein m/m ratio were able to induce Orb2 droplet formation (see Figure S2) when added to HSU-buffer. Again, Orb2B $\Delta$ RBD droplets are significantly smaller under these conditions.

Many protein droplets mature over time, undergoing a transition from a state in which proteins freely diffuse inside the droplet to a state with little to no protein diffusion (glass transition) 22. To characterize protein diffusion inside droplets, we measured fluorescence recovery after photobleaching (FRAP). We bleached the center of Oregon Green 488 labeled Orb2 droplets using an argon laser and monitored the recovery by confocal microscopy for 5 minutes afterwards. To our surprise, none of the Orb2 constructs showed any degree of recovery, even though FRAP experiments were performed within 1 minute of droplet formation. These results indicate that Orb2 is static within droplets almost immediately after undergoing phase separation (Figure 3). To further confirm these results, we did 4 consecutive 10 minute FRAP experiments on the same cluster of Orb2B droplets. The first had still not recovered after the last experiment ended (Figure S3.

In addition, we found several clusters of Orb2B droplets with overlap between individual droplet boundaries (Figure 3 and Figure S3). For many other proteins this stage typically marks the beginning of a droplet fusion event. None of the droplets with overlapping boundaries completed the fusion process. These results support that Orb2B becomes static within droplets relatively quickly after phase separation. As a positive control, we used a N-terminally 6xHis and GFP tagged FUS construct (His-GFP-FUS) for which we measured about $50 \%$ recovery in fluorescence after 22 seconds, similar to FRAP experiments on FUS droplet reported previously [20].

For some proteins, droplet maturation is followed by cross- $\beta$ fibril formation [18]. To test 
how Orb2 droplets evolve and if they eventually result in cross- $\beta$ fibrils, we monitored Orb2 droplets over time using fluorescence microscopy, electron microscopy (EM), and Thioflavin T (ThT) fluorescence. Fluorescence microscopy and EM images of Orb2B $\Delta$ RBD, Orb2A $\Delta$ RBD, and Orb2B in H-buffer are shown in Figure 4 In the case of Orb2B $\triangle \mathrm{RBD}$, the initial droplets formed halos at $12 \mathrm{~h}$ in our fluorescence images, which coincided with unbundled fibrils radiating out from a dark center as seen by EM. Similarly, Orb2A $\triangle$ RBD droplets turned into small fibrils and droplets at $12 \mathrm{~h}$. At $48 \mathrm{~h}$, we observed large objects in fluorescence microscopy, which coincided with thick, bundled fibrils in our EM images. In contrast, Orb2B droplets never progressed to form fibrils, but formed larger objects that were composed of merged droplets similar to those shown in Figure 3.

We attributed the disappearance of Orb2B $\triangle \mathrm{RBD}$ and Orb2A $\triangle \mathrm{RBD}$ droplets over several hours to the maturation of these droplets into cross- $\beta$ fibrils (Figure 4 ). When examined using $\mathrm{EM}$, Orb2B $\triangle \mathrm{RBD}$ fibrils were mostly unbundled, occasionally radiating out from a common center, presumably a droplet. In contrast, Orb2A $\triangle \mathrm{RBD}$ fibrils were highly bundled. As can be seen from Figure $\mathrm{S4}$ both fibril types did not show any fine structure or twist at higher magnification and had an average diameter of about $18 \mathrm{~nm}$.

As an additional measure of droplet to fibril transition, we measured ThT fluorescence and $\mathrm{OD}_{600}$ kinetics for each Orb2 construct in both HSU and H-buffer (Figure 5). We did not observe any increase in ThT fluorescence in HSU-buffer for any of the constructs. In H-buffer, Orb2B $\triangle \mathrm{RBD}$ and $\mathrm{Orb} 2 \mathrm{~A} \triangle \mathrm{RBD}$ showed an increase in fluorescence in a sigmoidal shaped curve typical for cross- $\beta$ fibril formation. In contrast, Orb2B showed only a negligible increase in fluoresce in H-buffer compared to HSU-buffer possibly due to light scattering from droplets. The $\mathrm{OD}_{600}$ curves, of Orb2B $\triangle \mathrm{RBD}$ and Orb2A $\triangle \mathrm{RBD}$ decreased in the first $20 \mathrm{~h}$ and increased for Orb2A $\triangle \mathrm{RBD}$ after about 25-40 h. Only a slight increase for Orb2B $\triangle \mathrm{RBD}$ was observed after about $60 \mathrm{~h}$. This initial decrease is compatible with the disappearance of Orb2B $\triangle \mathrm{RBD}$ and Orb2A $\triangle \mathrm{RBD}$ droplets, whereas the later increase in scattering for Orb2A $\triangle \mathrm{RBD}$ correlates with the appearance of large, highly bundled fibrils. The OD of Orb2B stayed constant during our measurements consistent with the formation of relatively stable droplets.

Phase separation of Orb2B $\triangle \mathrm{RBD}$ and Orb2A $\triangle \mathrm{RBD}$ ultimately led to the formation of cross$\beta$ fibrils. Next we asked, how does the structure of these fibrils compare to the cryo-EM structure of Orb2 fibrils purified from Drosophila brain [6] and the structure of recombinant Orb2 $\mathrm{A}_{1-88}$ fibrils we investigated previously [8]? To answer this question, we expressed and purified U${ }^{13} \mathrm{C}-{ }^{15} \mathrm{~N}$ labeled Orb2B $\Delta$ RBD and Orb2A $\triangle$ RBD. We then prepared fibrils via phase separation for solid-state NMR measurements. One-dimensional ${ }^{13} \mathrm{C}$ spectra of these fibrils are shown in Figure 6. Cross-polarization $(\mathrm{CP})$ spectra detect static protein domains that in the case of cross- 
$\beta$ fibrils often coincide with the fibril core. Refocused INEPT spectra, in contrast, are sensitive to dynamic protein regions that are often framing the static fibril core. As seen from the spectra, both Orb2B $\triangle \mathrm{RBD}$ and $\mathrm{Orb} 2 \mathrm{~A} \triangle \mathrm{RBD}$ fibrils have static and dynamic domains. The aliphatic region of the $\mathrm{CP}$ spectra of these two fibril types overlaps relatively well indicating that both fibrils have similar structure. Both CP spectra also show His side chain resonances compatible with a His-rich fibril core. However, the small differences between the spectra indicate that their fibril core structures are not exactly the same. The more intense INEPT spectrum of Orb2B $\triangle \mathrm{RBD}$ indicates that these fibrils have larger dynamic domains.

To learn more about the amino acid residues found in the fibril core, we recorded CP-based, $2 \mathrm{D}{ }^{13} \mathrm{C}-{ }^{13} \mathrm{C}$ DREAM (Figure 7) spectra that highlight the most immobile residues in the fibrils which often coincide with its core $[23,8,24$. These spectra allowed us to identify the amino acid residue composition of the core, which included Ala, Asn, Gln, His, Ile, Ser, Pro, Thr, and Val. To evaluate how the structure of these fibrils compared to those extracted from Drosophila by Hervás and co-workers, we predicted the NMR chemical shifts of Orb2B residues 178-204 of their cryo-EM structure (PDB access code 6VPS) using the program Shiftx2 25] and projected the expected cross peaks onto our spectra. As can be seen from Figure 7 , the predicted Gln $\mathrm{C} \alpha-\mathrm{C} \beta, \mathrm{C} \alpha-\mathrm{C} \gamma$, and His $\mathrm{C} \alpha-\mathrm{C} \beta$ peaks overlap well with the broad peak at about 55 and 32 ppm. In addition, the predicted cross peak of L198, in the center of the Orb2 core, overlapped perfectly with the Ile $\mathrm{C} \alpha-\mathrm{C} \beta$ and $\mathrm{C} \alpha-\mathrm{C} \gamma$ signals identified in our spectrum. Overall, these data suggest that the Orb2 fibril core determined by cryo-EM is also present in our fibrils. In addition, we identified many intense signals from residues that are not part of the Gln/His rich core namely Ala, Asn, Ile, Pro, Thr, and Val. The chemical shift of these resonances is generally compatible with an extended $\beta$-sheet conformation.

The 2D DREAM spectra confirm that the two fibrils give spectra that are very similar, indicating a similar core structure. Nevertheless, we were able to identify few additional cross peaks in the DREAM spectrum of Orb2A $\triangle \mathrm{RBD}$ that could not be seen in Orb2B $\triangle \mathrm{RBD}$. These resonances are highlighted with arrows in Figure 7 and come from Thr, Val, and Ile residues. Interestingly, these resonances do not clearly point to an additional fibril core located at the N-terminal region unique to Orb2A $\triangle \mathrm{RBD}$ as could be expected, because Thr is not found in this N-terminus. We are currently working on the site-specific assignment of these samples to determine the location and structure of the additional static domains and their differences.

How do the Gln resonances in our Orb2 fibrils spectra compare to Gln resonances found in spectra of $\mathrm{HTT}_{\mathrm{ex} 1}$ and Sup35p, two proteins that form fibrils with a Gln-rich core? Figure S5 A shows the overlay of $2 \mathrm{D}{ }^{13} \mathrm{C}^{13}{ }^{13} \mathrm{C}$ spectra of Orb2B $\Delta$ RBD and $\mathrm{HTT}_{\text {ex } 1}$ (Q25) fibrils, both of which were formed through phase separation. This overlay shows that the Gln peaks 
in Orb2B $\triangle \mathrm{RBD}$ do not correspond well to any of the two major Gln peaks (i.e. Gln A and Gln B) in the $\mathrm{HTT}_{\text {ex } 1}$ fibril spectra [26, 27, 28, 29, 30, 31]. Orb2B $\Delta \mathrm{RBD}$ 's $\mathrm{C} \alpha$ and $\mathrm{C} \beta$ chemical shift is compatible with an extended conformation and in between the shifts observed for Gln $\mathrm{A}$ and Gln B in $\mathrm{HTT}_{\mathrm{ex} 1}$. Its side chain $\mathrm{C} \delta$ shift is significantly higher than what has been observed for Gln A and GlnB in $\mathrm{HTT}_{\mathrm{ex} 1}$ and compatible with the minor Gln population in $\mathrm{HTT}_{\text {ex } 1}$ termed Gln C. This analysis suggests that the Gln conformations in the cross- $\beta$ cores of Orb2 and $\mathrm{HTT}_{\mathrm{ex} 1}$ are different. We also compared the Gln resonance assigned in the Q-rich fibril core of Sup35p [32] with our spectra (Figure S5B). Many of the Gln $\mathrm{C} \alpha-\mathrm{C} \beta$ and $\mathrm{C} \alpha-\mathrm{C} \gamma$ assignments fit well into the broad Gln resonance observed for Orb2B $\triangle \mathrm{RBD}$ suggesting that they have a similar structure.

\section{Discussion}

In the present study, we show that Orb2 can phase separate into droplets that quickly mature and transition into cross- $\beta$ fibrils in the absence of the C-terminal RNA binding domain. Because Orb2 has a domain structure similar to other RNA binding proteins that phase separate, droplet formation of Orb2 was predicted to occur [10. However, Majumdar and co-workers showed that intracellular Orb2A puncta showed little mobility when assessed using FRAP assays suggesting that these were self-assembled oligomers rather than droplets [4]. We reconcile these two views by showing that Orb2 phase separation does occur. However, in contrast to other proteins that undergo slow maturation from more liquid to more glass-like droplets with little to no protein mobility, the Orb2 droplets we describe either never go through a liquid phase or this state is so short-lived that we were not able to detect it. In this sense Orb2 droplets are similar to those formed by the nuclear pore complex protein nucleoporin [33], the protein velo1 found in Balbiani bodies [34, or stress induced A-bodies [35, 36. In contrast, $\mathrm{HTT}_{\text {ex1 }}$ (Q25), which can form protein droplets that mature into fibrils with Gln-rich core similar to Orb2, forms initially liquid-like assemblies [16].

In our hands, phase separation is a necessary requirement to go from soluble Orb2 $\triangle \mathrm{RBD}$ into amyloid fibrils. We previously showed that a shorter fragment of Orb2A (i.e. Orb2 $\mathrm{A}_{1-88}$ ) forms cross- $\beta$ fibrils over time in HSU-buffer [8]. However, the fibril core of Orb2 $\mathrm{A}_{1-88}$ was not located in the $\mathrm{Q} / \mathrm{H}$-rich domain but rather at the very $\mathrm{N}$-terminus unique to Orb2A. In contrast, Orb2 $\triangle \mathrm{RBD}$ fragments did not aggregate in HSU-buffer and required phase separation for fibril formation. Further, NMR spectra of Orb2 $\triangle$ RBD fibrils are compatible with the presence of the Q/H-rich fibril core described in the recent cryo-EM structure of Orb2 fibrils [6]. Our NMR spectra also show that there are additional static domains in Orb2B $\triangle \mathrm{RBD}$ and Orb2A $\triangle \mathrm{RBD}$ fibrils not explained by the Q/H-rich fibril core. These domains contain Ile, Pro, Val and 
multiple Ala, Ser, and Thr residues. This amino acid composition does not allow us to locate these domains within the sequence. There is little evidence that they are located in the first 8 residues of Orb2A because the prominent Phe peak that is characteristic for fibrils formed by these residues [8] was missing from our spectra. We are currently working on the assignment of these additional regions.

In addition to having slightly different fibril cores, Orb2B $\triangle \mathrm{RBD}$ and Orb2A $\Delta \mathrm{RBD}$ also form droplets that vary in size independent of conditions. Orb2A $\triangle \mathrm{RBD}$ fibrils are highly bundled, whereas Orb2B $\triangle \mathrm{RBD}$ fibrils show little tendency to bundle. Consequently, the different Orb2 $\mathrm{N}$-termini must play a role in droplet size and fibril bundling.

How do the NMR spectra of Orb2 $\triangle \mathrm{RBD}$ fibrils compare to the NMR spectra of $\mathrm{HTT}_{\text {ex1 }}$ and Sup35p fibrils? This comparison is of interest because the Q/H-rich fibril core of Orb2 is reminiscent of the polyQ fibril core of $\mathrm{HTT}_{\mathrm{ex} 1}$ and the Gln-rich core of Sup35p. Our comparison of the Gln cross peaks of $\mathrm{HTT}_{\mathrm{ex} 1}$ and Orb2B $\Delta \mathrm{RBD}$ fibril spectra indicates that the conformation of the Gln residues in both fibril cores is distinct, which would be in line with the fact that the Orb2 fibril core is an in-register parallel $\beta$-structure [6] whereas $\mathrm{HTT}_{\text {ex } 1}$ is not [37. This might also explain why the assignment of Gln resonances of Sup35p fibrils [32] fits our spectra better than $\mathrm{HTT}_{\text {ex1 }}$, since Sup35 fibrils were shown to form in-register parallel $\beta$-sheets [38. Ultimately, the best fit to the Gln resonances in our spectra was obtained by predicting chemical shifts from the cryo-EM structure of the Orb2 fibril core, suggesting that our fibrils are similar in structure to those found in vivo.

Where Orb2 fragments without the C-terminal RBD form cross- $\beta$ fibrils after droplet formation, full-length Orb2B remains in a state of matured droplets, which merge but neither completely fuse nor transition into cross- $\beta$ fibrils. This observation is compatible with previous in vivo work showing that Orb2B alone cannot form functional aggregates that activate the translation of target mRNA [4. Because Orb2B $\triangle \mathrm{RBD}$ forms fibrils via droplet formation, the C-terminal RBD likely plays an important role in preventing fibril formation of Orb2B.

In summary, our data establish droplet formation as a possible mechanism for inducing the Orb2 fibril formation in vivo. However, this mechanism needs to be confirmed in vivo. Based on our ability to make monomeric Orb2 and induce its phase transition, our future work aims at building a functional Orb2 protein complex in vitro and describe the structural interactions of its components. 


\section{Methods and Materials}

\subsection{Protein constructs}

The sequences for Orb2A $\triangle \mathrm{RBD}$ and Orb2B $\triangle \mathrm{RBD}$ were codon optimized for expression in E. coli, synthesized, and cloned into pET28b expression vectors with a C-terminal 6x histidinetag (6xHis-tag) by Genscript USA Inc. Full-length Orb2B was cloned from a pDEST vector (provided by the lab of Dr. Kausik Si) into a pET28b vector.

\subsection{Protein expressions and purification}

\subsubsection{Orb2}

The Orb2B was expressed in Rosetta 2 E. Coli (DE3) whereas, Orb2A $\triangle$ RBD and Orb2B $\Delta$ RBD were expressed in T7 express or BL21 (DE3) (EMD Millipore, Billerica, MA). A single colony was used to inoculate $50 \mathrm{ml} \mathrm{LB}$ medium with the appropriate antibiotic (chloramphenicol $35 \mathrm{mg} / \mathrm{ml}$ and kanamycin $50 \mathrm{mg} / \mathrm{ml}$ ) and grown overnight at $30^{\circ} \mathrm{C}$. The next day, $1-5 \mathrm{ml}$ of this culture was expanded into $500 \mathrm{ml} \mathrm{LB}$ with the appropriate antibiotic and cells were grown at $37^{\circ} \mathrm{C}$ to an $\mathrm{OD}_{600}$ of 0.6 . Protein expression was subsequently induced with the addition of $1 \mathrm{mM}$ IPTG and cells were grown for an additional $18-20 \mathrm{~h}$ at $18^{\circ} \mathrm{C}$. Cells were then harvested via centrifugation in a Sorvall SLC-6000 rotor (Thermo Fisher Scientific) at $4000 \mathrm{rpm}$ for $20 \mathrm{~min}$ at $4^{\circ} \mathrm{C}$ and were used immediately or stored at $-80^{\circ} \mathrm{C}$ for future use.

Cell pellets ranging from 2.5-3 g were resuspended in HSU buffer (1 M urea, $100 \mathrm{mM} \mathrm{KCl,}$ $10 \mathrm{mM}$ HEPES, $0.1 \% \mathrm{v} / \mathrm{v}$ Tween-20 and $0.05 \% \mathrm{v} / \mathrm{v} \beta$-mercaptoethanol, $\mathrm{pH}$ 7.6) containing $1 \mathrm{mg} / \mathrm{ml}$ lysozyme and $2 \mu \mathrm{l} / \mathrm{ml}$ of $10 \mathrm{X}$ DNase I. Cells were then sonicated using a Q125 ultrasonic homogenizer (QSonica, Newton, CT) and the cell lysate was centrifuged at 20,000 rpm for 20 min at $4^{\circ} \mathrm{C}$ using a Sorvall SS-34 rotor (Thermo Fisher Scientific). The supernatant was collected and filtered through a $0.22 \mu \mathrm{m}$ vacuum filtration system (Corning INC). The 6xHis-tagged protein samples were loaded onto pre-equilibrated $\mathrm{Ni}^{2+}$ affinity resin (HisTrap $\mathrm{HP} 5 \mathrm{ml}$, GE Healthcare). The column was sequentially washed with HSU buffer containing $0.5 \%$ triton-X, $500 \mathrm{mM} \mathrm{NaCl}, 20 \mathrm{mM}$ imidazole, and $1 \mathrm{M} \mathrm{NaCl}$ (each wash was 5 column volumes). The protein was then eluted with $500 \mathrm{mM}$ imidazole and $1 \mathrm{M} \mathrm{NaCl}$ in HSU buffer. Protein elution was traced using $280 \mathrm{~nm}$ UV absorption. Fractions containing the protein of interest were pooled together and loaded onto a pre-equilibrated size exclusion column (HiPrep 16/60 Sephacryl S-300, GE Healthcare). The protein was then eluted using HSU buffer and the protein fractions were used immediately or frozen in liquid nitrogen and stored at $-80^{\circ} \mathrm{C}$.

\subsubsection{HTTex1}

$\mathrm{HTT}_{\text {ex1 }}$ (Q25) was expressed and purified as described earlier [27, 39]. Reversed-phase purified and lyophilized $\mathrm{HTT}_{\mathrm{ex} 1}(\mathrm{Q} 25)$ was dissolved in $0.5 \%$ trifluoroacetic acid in methanol 
(TFA-MeOH) and dried in a borosilicate glass tube using nitrogen. The dried protein film was reconstituted in $20 \mathrm{mM}$ phosphate buffer, $\mathrm{pH}$ 7.4, containing $150 \mathrm{mM} \mathrm{NaCl}$ and $10 \%$ dextran such that the final protein concentration was $300 \mu \mathrm{M}$. The solution was incubated at room temperature for 14 hours. Under these conditions, $\mathrm{HTT}_{\mathrm{ex} 1}$ (Q25) forms fibrils via phase separation. These fibrils were harvested by centrifugation at 40,000 rpm for $30 \mathrm{~min}$ in a Beckman Coulter TLA-100.3 rotor. The fibrils were washed with $20 \mathrm{mM}$ phosphate buffer, $\mathrm{pH}$ 7.4, containing $20 \mathrm{mM} \mathrm{NaCl}$ before they were packed into a solid-state NMR rotor.

\subsection{Fluorescence and DIC wide field microscopy}

Protein samples that were used for microscopy either eluted from SEC in a HSU buffer that contained $5 \mathrm{mM}$ TCEP or exchanged into a HSU-buffer with $5 \mathrm{mM}$ TCEP using a desalting column. The protein samples were then labeled with either $5 \mathrm{mM}$ thiol-reactive or $5 \mathrm{mM}$ aminereactive fluorescent dyes over night at $4^{\circ} \mathrm{C}$ with light shaking. Orb2B and Orb2B $\triangle \mathrm{RBD}$ were labeled with thiol-reactive Oregon Green 488 through maleimide chemistry (Thermofisher). Due to the lack of cystine residues in the Orb2A $\triangle \mathrm{RBD}$ protein construct, it was labeled with lysinereactive succinimidyl ester Oregon Green 488 (Thermofisher). The excitation and emission maxima of these fluorescent bioconjugates are $496 \mathrm{~nm}$ and $524 \mathrm{~nm}$, respectively. To induce droplet formation, protein was either exchanged into H-buffer $(10 \mathrm{mM}$ HEPES, $0.03 \% \mathrm{v} / \mathrm{v}$ $\mathrm{NaN}_{3}$ and $0.05 \% \mathrm{v} / \mathrm{v} \beta$-mercaptoethanol, $\mathrm{pH} 6.5$ ), or into HSU buffer, $\mathrm{pH} 6.5$ followed by the addition of $10 \% \mathrm{v} / \mathrm{v}$ PEG 8000 or 1:10 m/m PolyA:protein.

Fluorescence images were taking by exiting at $488 \mathrm{~nm}$ and imaging at $505 \mathrm{~nm}$ using a Zeiss AxioImager widefield light microscope with white light laser. DIC microscopy images were also recorded on Zeiss AxioImager microscope seconds after the corresponding fluorescence images were taken, by switching from a Zeiss Filter set $38 \mathrm{HE}$ (optimized for emission at $488 \mathrm{~nm}$ ) to a default Zeiss DIC filter. Image of protein droplets were captured at 0,12 and 48 hours post exchanged into the H-buffer. Images were analyzed using Fiji image analysis software [40, 41] including the BioVoxxel plugin. Microscopy was repeated on three biological replicates.

\subsection{Fluorescence recovery after photobleaching (FRAP)}

Oregon Green labeled protein samples were prepared analogous to those described above. Protein samples were then exchanged into H-buffer with $5 \mathrm{mM}$ TCEP using a PD-10 G-25 media desalting column and FRAP measurements were done using Leica-SP8X confocal laser scanning microscope with a $63 \mathrm{x}$ oil immersion objective. Droplets were bleached with an average diameter of $5 \mathrm{~nm}$, to avoid whole-droplet bleaching artifacts in droplets of smaller diameters 42. Bleached regions of interest (ROI) of $0.5 \mu \mathrm{m}$ were created with a pinhole Argon laser with a scanning speed ranging from 50-150 ms using the Leica software. FRAP data were analyzed and 
plotted with in house python scripts using the pandas, numpy, scipy, and matplotlib libraries. Recovery curves \pm SD were generated by normalizing and averaging across three biological replicates.

\subsection{Thioflavin $T$ fluorescence assay}

Protein samples were exchanged into a H-buffer using a PD-10 G-25 media desalting column (GE Healthcare) to induce droplet formation. $200 \mu \mathrm{l}$ of $10-20 \mu \mathrm{M}$ protein were mixed with thioflavin $\mathrm{T}$ (Tht) at a final concentration of $50 \mu \mathrm{M}$ and added to a clear flat bottom 96-well plate (Greiner Bio-One). The solution was then excited at $442 \mathrm{~nm}$, and the emission at 482 nm was measured every 10 minutes for 80-160 hours using an Eppendorf AF2200 plate reader at $25^{\circ} \mathrm{C}$. Three independent measurements were recorded for each protein, and normalized and plotted using in house python scripts (available upon request).

\subsection{Electron Microscopy}

Electron microscopy specimens were prepared by submerging a Formvar carbon coated copper grid (Electron Microscopy Sciences) in $10 \mu \mathrm{l}$ of protein solution and incubating it for 5 minutes. These grids were then stained with $10 \mu$ l of a $1 \%$ uranyl acetate solution for 2 minutes at room temperature. The grids were then tapped on two additional $10 \mu 1$ uranyl acetate drops and finally, rinsed in deionized water. Filter paper was used to remove the excess of stain and water before imaging. The negatively stained samples were examined for droplets or fibrils with a JEOL JEM-1400 TEM electron microscope. Images were acquired using a Gatan Orius digital camera at magnification of 5000-10,000X. Fibril images were analyzed using ImageJ including the FibrilJ plugin 43 .

\subsection{Solid-state NMR spectroscopy}

NMR spectra were recorded on an Agilent DD2 $600 \mathrm{MHz}$ solid-state NMR spectrometer using a T3 $1.6 \mathrm{~mm}$ probe. All hard ${ }^{1} \mathrm{H}$ and ${ }^{13} \mathrm{C}$ radio frequency (rf) pulses had amplitudes of $200 \mathrm{kHz}$ and $100 \mathrm{kHz}$, respectively. ${ }^{1} \mathrm{H}^{13} \mathrm{C}$ cross polarizations (CPs) were done with $60 \mathrm{kHz}$ rf-amplitude on ${ }^{13} \mathrm{C}$ and a ${ }^{1} \mathrm{H}$ rf-amplitude that was larger by the MAS frequency. A $10 \%$ amplitude ramp was applied during $1 \mathrm{~ms}$ of contact time. Proton decoupling during acquisition was done using the XiX decoupling scheme [4] with rf-field amplitudes of $140 \mathrm{kHz}$. A recycle delay of $3 \mathrm{~s}$ and a $0^{\circ} \mathrm{C}$ set temperature was used for all spectra.

One dimensional CP, DB, and refocused INEPT spectra were recorded at $25 \mathrm{kHz}$ MAS with a spectral width of $50 \mathrm{kHz}, 1000$ complex points, and 1024 acquisitions. ${ }^{13} \mathrm{C}-{ }^{13} \mathrm{C}$ DREAM (dipolar recoupling enhanced by amplitude modulation) [45] spectra were recorded at $30 \mathrm{kHz}$ MAS using a spectral width of $50 \mathrm{kHz}$ in both dimensions and a mixing time of $4.5 \mathrm{~ms}$. For each 
of the 800 indirect TPPI increments 128 and 64 acquisitions were recorded for the Orb2B $\triangle \mathrm{RBD}$ and Orb2A $\triangle \mathrm{RBD}$ samples, respectively.

2D DARR (dipolar assisted rotational resonance) spectra [46] of Orb2B $\triangle \mathrm{RBD}$ and $\mathrm{HTT}_{\text {ex1 }}$ (Q25) were recorded at $25 \mathrm{kHz}$ MAS with a spectral width of $50 \mathrm{kHz}$, and a mixing time of $50 \mathrm{~ms}$. For Orb2B $\triangle \mathrm{RBD} 400$ indirect, complex increments were recorded with 64 acquisitions each. For $\mathrm{HTT}_{\mathrm{ex} 1}$ (Q25) 500 indirect, complex increments were recorded with 64 acquisitions each.

All spectra were processed using Lorentz to Gauss transform window functions. Adamantane spectra were used to reference the chemical shifts externally to DSS (4,4-dimethyl-4-silapentane1-sulfonic acid) [47. The spectra were analyzed using CARA [25] and plotted using in house python scripts (available upon request) based on the numpy, matplotlib, and nmrglue packages [4, 49].

\section{Acknowledgments}

A.B.S. would like to acknowledge funding from the National Institutes of Health (R01NS084345, R01GM110521) and the CHDI Foundation (Award A-12640). A.S.F. would like to acknowledge funding from the National Institutes of Health (F31GM120858).

\section{References}

\section{References}

[1] K. Si, E. R. Kandel, The Role of Functional Prion-Like Proteins in the Persistence of Memory., Cold Spring Harbor perspectives in biology 8 (4) (2016). doi:10.1101/cshperspect. a021774.

[2] K. Keleman, S. Krüttner, M. Alenius, B. J. Dickson, Function of the Drosophila CPEB protein Orb2 in long-term courtship memory., Nature Neuroscience 10 (12) (2007) 1587-93. doi:10.1038/nn1996.

[3] S. Krüttner, B. Stepien, J. N. Noordermeer, M. A. Mommaas, K. Mechtler, B. J. Dickson, K. Keleman, Drosophila CPEB Orb2A Mediates Memory Independent of Its RNA-Binding Domain, Neuron 76 (2) (2012) 383-395. doi:10.1016/j.neuron.2012.08.028.

[4] A. Majumdar, W. C. Cesario, E. White-Grindley, H. Jiang, F. Ren, M. R. Khan, L. Li, E. M.-L. Choi, K. Kannan, F. Guo, J. Unruh, B. Slaughter, K. Si, Critical Role of Amyloidlike Oligomers of Drosophila Orb2 in the Persistence of Memory., Cell 148 (3) (2012) 51529. doi:10.1016/j.cell.2012.01.004. 
[5] R. Hervás, L. Li, A. Majumdar, M. d. C. Fernández-Ramírez, J. R. Unruh, B. D. Slaughter, A. Galera-Prat, E. Santana, M. Suzuki, Y. Nagai, M. Bruix, S. Casas-Tintó, M. Menéndez, D. V. Laurents, K. Si, M. Carrión-Vázquez, Molecular Basis of Orb2 Amyloidogenesis and Blockade of Memory Consolidation, PLOS Biology 14 (1) (2016) e1002361. doi: 10.1371/journal.pbio.1002361.

[6] R. Hervas, M. J. Rau, Y. Park, W. Zhang, A. G. Murzin, J. A. J. Fitzpatrick, S. H. W. Scheres, K. Si, Cryo-EM structure of a neuronal functional amyloid implicated in memory persistence in Drosophila, Science 367 (6483) (2020) 1230-1234. doi:10.1126/science. aba3526.

[7] E. White-Grindley, L. Li, R. Mohammad Khan, F. Ren, A. Saraf, L. Florens, K. Si, Contribution of Orb2A Stability in Regulated Amyloid-Like Oligomerization of Drosophila Orb2., PLoS biology 12 (2) (2014) e1001786. doi:10.1371/journal.pbio.1001786.

[8] S. A. Cervantes, T. H. Bajakian, M. A. Soria, A. S. Falk, R. J. Service, R. Langen, A. B. Siemer, Identification and Structural Characterization of the N-terminal Amyloid Core of Orb2 isoform A., Scientific reports 6 (1) (2016) 38265. doi:10.1038/srep38265.

[9] L. Li, C. P. Sanchez, B. D. Slaughter, Y. Zhao, M. R. Khan, J. R. Unruh, B. Rubinstein, K. Si, A Putative Biochemical Engram of Long-Term Memory, Current Biology 26 (23) (2016) 3143-3156. doi:10.1016/j.cub.2016.09.054.

[10] O. D. King, A. D. Gitler, J. Shorter, The tip of the iceberg: RNA-binding proteins with prion-like domains in neurodegenerative disease., Brain Research 1462 (2012) 61-80. doi: $10.1016 /$ j.brainres.2012.01.016.

[11] M. Kato, T. W. Han, S. Xie, K. Shi, X. Du, L. C. Wu, H. Mirzaei, E. J. Goldsmith, J. Longgood, J. Pei, N. V. Grishin, D. E. Frantz, J. W. Schneider, S. Chen, L. Li, M. R. Sawaya, D. Eisenberg, R. Tycko, S. L. McKnight, Cell-free formation of RNA granules: Low complexity sequence domains form dynamic fibers within hydrogels, Cell 149 (4) (2012) 753-767. doi:10.1016/j.cell.2012.04.017.

[12] P. Li, S. Banjade, H.-C. Cheng, S. Kim, B. Chen, L. Guo, M. Llaguno, J. V. Hollingsworth, D. S. King, S. F. Banani, P. S. Russo, Q.-X. Jiang, B. T. Nixon, M. K. Rosen, Phase transitions in the assembly of multivalent signalling proteins, Nature 483 (7389) (2012) 336-340. doi:10.1038/nature10879.

[13] Y. Lin, D. S. W. Protter, M. K. Rosen, R. Parker, Formation and Maturation of PhaseSeparated Liquid Droplets by RNA-Binding Proteins, Molecular Cell 60 (2) (2015) 208-219. doi:10.1016/j.molcel.2015.08.018. 
[14] X. Wu, Q. Cai, Z. Feng, M. Zhang, Liquid-Liquid Phase Separation in Neuronal Development and Synaptic Signaling, Developmental Cell 55 (1) (2020) 18-29. doi:10.1016/j. devcel.2020.06.012.

[15] X. Chen, X. Wu, H. Wu, M. Zhang, Phase separation at the synapse, Nature Neuroscience (2020) 1-10 doi:10.1038/s41593-019-0579-9.

[16] T. R. Peskett, F. Rau, J. O'Driscoll, R. Patani, A. R. Lowe, H. R. Saibil, A Liquid to Solid Phase Transition Underlying Pathological Huntingtin Exon1 Aggregation, Molecular Cell 70 (4) (2018) 588-601.e6. doi:10.1016/j.molcel.2018.04.007.

[17] H. Zhang, S. Elbaum-Garfinkle, E. M. Langdon, N. Taylor, P. Occhipinti, A. A. Bridges, C. P. Brangwynne, A. S. Gladfelter, RNA Controls PolyQ Protein Phase Transitions, Molecular Cell 60 (2) (2015) 220-230. doi:10.1016/j.molcel.2015.09.017.

[18] R. Halfmann, A glass menagerie of low complexity sequences, Current Opinion in Structural Biology 38 (2016) 9-16. doi:10.1016/j.sbi.2016.05.002.

[19] S. F. Banani, H. O. Lee, A. A. Hyman, M. K. Rosen, Biomolecular condensates: Organizers of cellular biochemistry, Nature Reviews Molecular Cell Biology 18 (5) (2017) 285-298. doi:10.1038/nrm.2017.7.

[20] A. Patel, H. O. Lee, L. Jawerth, S. Maharana, M. Jahnel, M. Y. Hein, S. Stoynov, J. Mahamid, S. Saha, T. M. Franzmann, A. Pozniakovski, I. Poser, N. Maghelli, L. A. Royer, M. Weigert, E. W. Myers, S. Grill, D. Drechsel, A. A. Hyman, S. Alberti, A Liquid-to-Solid Phase Transition of the ALS Protein FUS Accelerated by Disease Mutation, Cell 162 (5) (2015) 1066-1077. doi:10.1016/j.cell.2015.07.047.

[21] Y. Takashimizu, M. Iiyoshi, New parameter of roundness R: Circularity corrected by aspect ratio, Progress in Earth and Planetary Science 3 (1) (2016) 2. doi:10.1186/ s40645-015-0078-x.

[22] W. M. Babinchak, W. K. Surewicz, Liquid-Liquid Phase Separation and Its Mechanistic Role in Pathological Protein Aggregation, Journal of Molecular Biology 432 (7) (2020) 1910-1925. doi:10.1016/j.jmb.2020.03.004.

[23] A. B. Siemer, A. A. Arnold, C. Ritter, T. Westfeld, M. Ernst, R. Riek, B. H. Meier, Observation of highly flexible residues in amyloid fibrils of the HET-s prion, Journal of the American Chemical Society 128 (40) (2006) 13224-13228. doi:10.1021/ja063639x.

[24] A. B. Siemer, Advances in studying protein disorder with solid-state NMR, Solid State Nuclear Magnetic Resonance 106 (2020) 101643. doi:10.1016/j.ssnmr.2020.101643. 
[25] B. Han, Y. Liu, S. W. Ginzinger, D. S. Wishart, SHIFTX2: Significantly improved protein chemical shift prediction, Journal of Biomolecular NMR 50 (1) (2011) 43. doi:10.1007/ s10858-011-9478-4.

[26] J. M. Isas, R. Langen, A. B. Siemer, Solid-State Nuclear Magnetic Resonance on the Static and Dynamic Domains of Huntingtin Exon-1 Fibrils., Biochemistry 54 (25) (2015) 3942-9. doi:10.1021/acs.biochem.5b00281.

[27] J. M. Isas, A. Langen, M. C. Isas, N. K. Pandey, A. B. Siemer, Formation and Structure of Wild Type Huntingtin Exon-1 Fibrils., Biochemistry 56 (28) (2017) 3579-3586. doi: 10.1021/acs.biochem.7b00138.

[28] R. Schneider, M. C. Schumacher, H. Mueller, D. Nand, V. Klaukien, H. Heise, D. Riedel, G. Wolf, E. Behrmann, S. Raunser, R. Seidel, M. Engelhard, M. Baldus, Structural characterization of polyglutamine fibrils by solid-state NMR spectroscopy, Journal of Molecular Biology 412 (1) (2011) 121-136. doi:10.1016/j.jmb.2011.06.045.

[29] V. N. Sivanandam, M. Jayaraman, C. L. Hoop, R. Kodali, R. Wetzel, P. C. A. Van Der Wel, The aggregation-enhancing huntingtin N-terminus is helical in amyloid fibrils, Journal of the American Chemical Society 133 (12) (2011) 4558-4566. doi:10.1021/ja110715f.

[30] C. Hoop, H.-K. Lin, K. Kar, Z. Hao, M. Poirier, R. Wetzel, P. C. A. V. D. Wel, Polyglutamine Amyloid Core Boundaries and Flanking Domain Dynamics in Huntingtin Fragment Fibrils Determined by Solid-State Nuclear Magnetic Resonance, Biochemistry 53 (42) (2014) 6653-6666. doi:10.1021/bi501010q.

[31] C. L. Hoop, H.-K. Lin, K. Kar, G. Magyarfalvi, J. M. Lamley, J. C. Boatz, A. Mandal, J. R. Lewandowski, R. Wetzel, P. C. A. van der Wel, Huntingtin exon 1 fibrils feature an interdigitated $\beta$-hairpin-based polyglutamine core, Proceedings of the National Academy of Sciences 113 (6) (2016) 1546-1551. doi:10.1073/pnas.1521933113.

[32] A. K. Schütz, B. Habenstein, N. Luckgei, L. Bousset, Y. Sourigues, A. B. Nielsen, R. Melki, A. Böckmann, B. H. Meier, Solid-state NMR sequential assignments of the amyloid core of full-length Sup35p, Biomolecular NMR Assignments 8 (2) (2014) 349-356. doi:10.1007/ s12104-013-9515-1.

[33] M. Schmidt, A. Rohou, K. Lasker, J. K. Yadav, C. Schiene-Fischer, M. Fändrich, N. Grigorieff, Peptide dimer structure in an A $\beta(1-42)$ fibril visualized with cryo-EM, Proceedings of the National Academy of Sciences 112 (38) (2015) 11858-11863. doi:10.1073/pnas. 1503455112 
[34] E. Boke, M. Ruer, M. Wühr, M. Coughlin, R. Lemaitre, S. P. Gygi, S. Alberti, D. Drechsel, A. A. Hyman, T. J. Mitchison, Amyloid-like Self-Assembly of a Cellular Compartment, Cell 166 (3) (2016) 637-650. doi:10.1016/j.cell.2016.06.051.

[35] T. E. Audas, D. E. Audas, M. D. Jacob, J. J. D. Ho, M. Khacho, M. Wang, J. K. Perera, C. Gardiner, C. A. Bennett, T. Head, O. N. Kryvenko, M. Jorda, S. Daunert, A. Malhotra, L. Trinkle-Mulcahy, M. L. Gonzalgo, S. Lee, Adaptation to Stressors by Systemic Protein Amyloidogenesis, Developmental Cell 39 (2) (2016) 155-168. doi:10.1016/j.devcel. 2016.09 .002

[36] J. B. Woodruff, A. A. Hyman, E. Boke, Organization and Function of Non-dynamic Biomolecular Condensates, Trends in Biochemical Sciences 43 (2) (2018) 81-94. doi: 10.1016/j.tibs.2017.11.005.

[37] C. W. Bugg, J. M. Isas, T. Fischer, P. H. Patterson, R. Langen, Structural features and domain organization of huntingtin fibrils, Journal of Biological Chemistry 287 (38) (2012) 31739-31746. doi:10.1074/jbc.M112.353839.

[38] F. Shewmaker, D. Kryndushkin, B. Chen, R. Tycko, R. B. Wickner, Two prion variants of Sup35p have in-register parallel beta-sheet structures, independent of hydration, Biochemistry 48 (23) (2009) 5074-5082. doi:10.1021/bi900345q

[39] N. K. Pandey, J. M. Isas, A. Rawat, R. V. Lee, J. Langen, P. Pandey, R. Langen, The 17-residue-long $\mathrm{N}$ terminus in huntingtin controls step-wise aggregation in solution and on membranes via different mechanisms, Journal of Biological Chemistry 293 (7) (2018) 2597-2605. doi:10.1074/jbc.M117.813667.

[40] J. Schindelin, I. Arganda-Carreras, E. Frise, V. Kaynig, M. Longair, T. Pietzsch, S. Preibisch, C. Rueden, S. Saalfeld, B. Schmid, J.-Y. Tinevez, D. J. White, V. Hartenstein, K. Eliceiri, P. Tomancak, A. Cardona, Fiji: An open-source platform for biological-image analysis, Nature Methods 9 (7) (2012) 676-682. doi:10.1038/nmeth.2019

[41] C. T. Rueden, J. Schindelin, M. C. Hiner, B. E. DeZonia, A. E. Walter, E. T. Arena, K. W. Eliceiri, ImageJ2: ImageJ for the next generation of scientific image data, BMC Bioinformatics 18 (1) (2017) 529. doi:10.1186/s12859-017-1934-z

[42] N. O. Taylor, M.-T. Wei, H. A. Stone, C. P. Brangwynne, Quantifying Dynamics in PhaseSeparated Condensates Using Fluorescence Recovery after Photobleaching, Biophysical Journal 117 (7) (2019) 1285-1300. doi:10.1016/j.bpj.2019.08.030. 
[43] P. Sokolov, M. Belousov, S. Bondarev, G. Zhouravleva, N. Kasyanenko, FibrilJ: ImageJ plugin for fibrils' diameter and persistence length determination, Computer Physics Communications 214 (2017) 199-206. doi:10.1016/j.cpc.2017.01.011.

[44] A. Detken, E. H. Hardy, M. Ernst, B. H. Meier, Simple and efficient decoupling in magicangle spinning solid- state NMR: The XiX scheme, Chem. Phys. Lett. 356 (3-4) (2002) 298-304. doi:10.1016/S0009-2614(02)00335-4.

[45] R. Verel, M. Ernst, B. H. Meier, Adiabatic dipolar recoupling in solid-state NMR: The DREAM scheme, Journal of Magnetic Resonance (San Diego, Calif.: 1997) 150 (1) (2001) 81-99. doi:10.1006/jmre.2001.2310.

[46] K. Takegoshi, S. Nakamura, T. Terao, 13C-1H dipolar-assisted rotational resonance in magic-angle spinning NMR, Chemical Physics Letters 344 (5) (2001) 631-637. doi:10. 1016/S0009-2614(01)00791-6.

[47] R. K. Harris (Ed.), Encyclopedia of Magnetic Resonance, John Wiley \& Sons, Ltd, Chichester, UK, 2007.

[48] J. D. Hunter, Matplotlib: A 2D Graphics Environment, Computing in Science Engineering 9 (3) (2007) 90-95. doi:10.1109/MCSE.2007.55

[49] J. J. Helmus, C. P. Jaroniec, Nmrglue: An open source Python package for the analysis of multidimensional NMR data, Journal of Biomolecular NMR 55 (4) (2013) 355-367. doi:10.1007/s10858-013-9718-x. 
bioRxiv preprint doi: https://doi.org/10.1101/2021.02.19.430336; this version posted February 19, 2021. The copyright holder for this preprint (which was not certified by peer review) is the author/funder, who has granted bioRxiv a license to display the preprint in perpetuity. It is made available under aCC-BY-NC 4.0 International license.

\section{Figures}

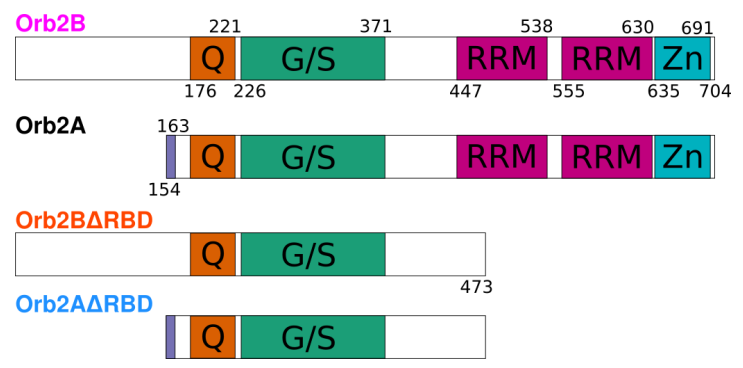

Figure 1: Domain structure of Orb2 isoforms and fragments used in this study. The glutamine-rich region (Q, orange), glycine/serine-rich region ( $\mathrm{G} / \mathrm{S}$, green), RRM domains (magenta), and zinc-finger domain (cyan) common to both Orb2A and Orb2B are highlighted as well as the unique first 9 amino acids of Orb2A (purple), which are essential for LTM.
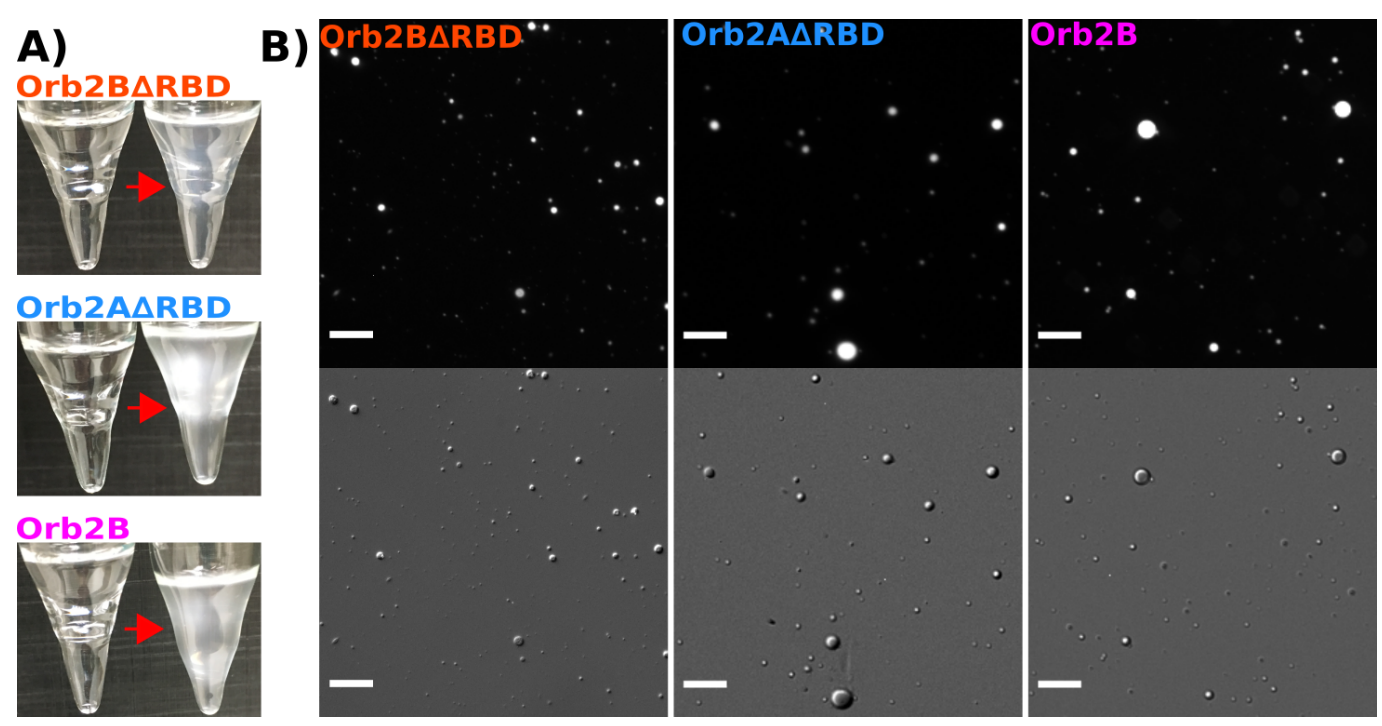

Figure 2: Orb2B $\triangle \mathrm{RBD}$, Orb2A $\triangle \mathrm{RBD}$ and Orb2B can undergo liquid-liquid phase separation at low ionic strength. (A) Test tubes of Orb2 fragments before and after exchange from HSU into H-buffer. (B) Fluorescence and DIC microscopy images of droplets formed by Orb2B $\triangle \mathrm{RBD}$, Orb2A $\triangle \mathrm{RBD}$ and Orb2B immediately after desalting from HSU-Buffer to H-buffer. Scale bars represent $20 \mu \mathrm{m}$. 

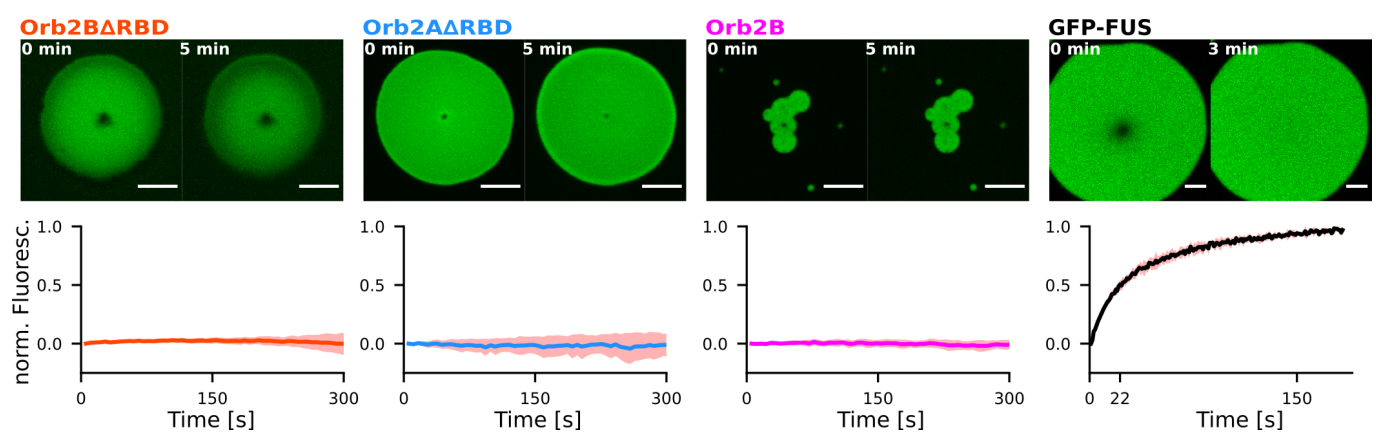

Figure 3: Droplets formed by Orb2B $\triangle \mathrm{RBD}$, Orb2A $\triangle \mathrm{RBD}$, and Orb2B show no protein diffusion via FRAP. Top: Fluorescence microscopy images right after and 5 min after bleaching. Scale bars represent $5 \mu \mathrm{m}$. Bottom: Average and standard deviation of the fluorescence intensity after bleaching (where 0 is the intensity after bleaching and 1 is the intensity of an unbleached region). None of the fragments showed measurable fluorescence recovery immediately after exchange into H-buffer. GFP labeled FUS, used as control, fully recovered after 3 min with $50 \%$ recovery after $22 \mathrm{~s}$.
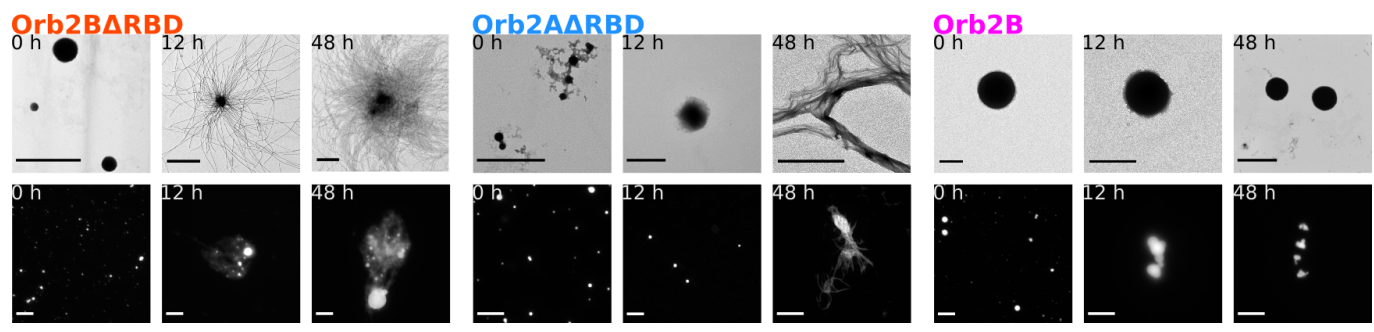

Figure 4: Orb2 $\triangle \mathrm{RBD}$ droplets mature into fibrils whereas Orb2B droplets do not. EM (upper row) and fluorescence microscopy (lower row) images of Orb2 constructs at 0,12 , and $48 \mathrm{~h}$ after exchange into H-buffer. Scale bars of EM and fluorescence microscopy images are $2 \mu \mathrm{m}$ and $20 \mu \mathrm{m}$, respectively. Orb2B $\Delta \mathrm{RBD}$ and Orb2A $\triangle \mathrm{RBD}$ droplets disappear giving way to fibrils seen by EM that correlate with large fuzzy objects seen by fluorescence microscopy. In contrast, no fibrils were observed for Orb2, whose droplets seemed to merge but not fuse over time. 

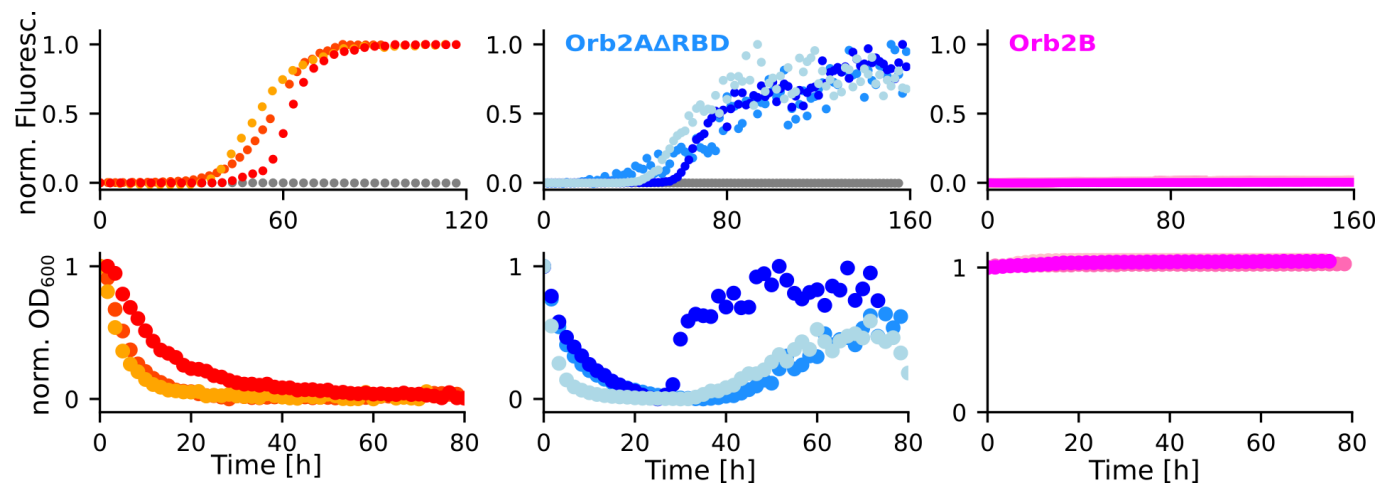

Figure 5: Tht fluorescence and OD measurements confirm that Orb2B $\triangle \mathrm{RBD}$ and Orb2A $\triangle \mathrm{RBD}$ droplets disappear over time giving way to cross- $\beta$ fibrils whereas Orb2B droplets are stable. Top: Tht fluorescence kinetics for Orb2B $\triangle \mathrm{RBD}$ and Orb2A $\triangle \mathrm{RBD}$ were normalized to their maxima, Orb2B kinetics according to the maximum of Orb2A $\triangle \mathrm{RBD}$ because the fluorescence intensity did not increase significantly relative to background. Bottom: $\mathrm{OD}_{600}$ kinetics as a measure of sample turbidity. Data were normalized to their first point. Where Orb2B $\Delta \mathrm{RBD}$ and Orb2A $\triangle \mathrm{RBD}$ show an initial decrease in turbidity, Orb2 turbidity was constant compatible with stable droplet formation.

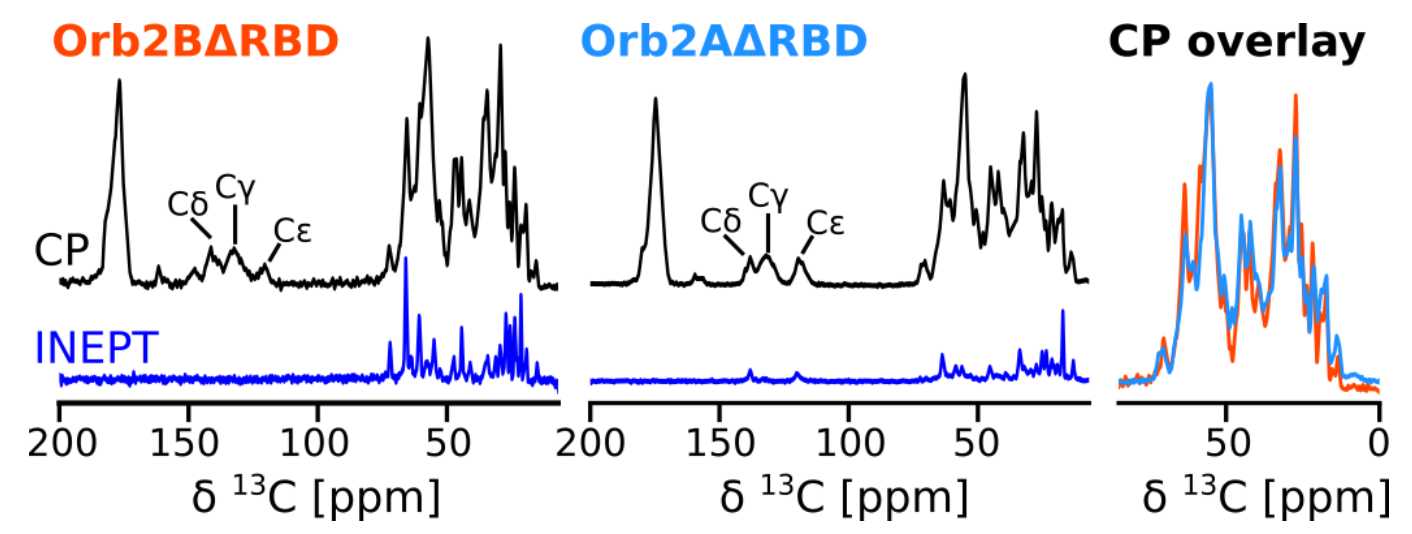

Figure 6: $1 \mathrm{D}{ }^{13} \mathrm{C}$ spectra of Orb2B $\Delta$ RBD and Orb2A $\triangle$ RBD fibrils indicate that both have similar structure with larger intrinsically disordered regions found in Orb2B $\Delta$ RBD. Cross polarization (CP, black) spectra detect static regions of the sample typically located in the fibril core. Histidine side chain resonances are highlighted in the aromatic region of the CP spectrum between 150 and $100 \mathrm{ppm}$. The refocused INEPT spectrum (INEPT, blue) detects highly dynamic, intrinsically disordered regions that are part of the fibril. Overlay of the two CP spectra indicates that both fibrils have similar structures. 

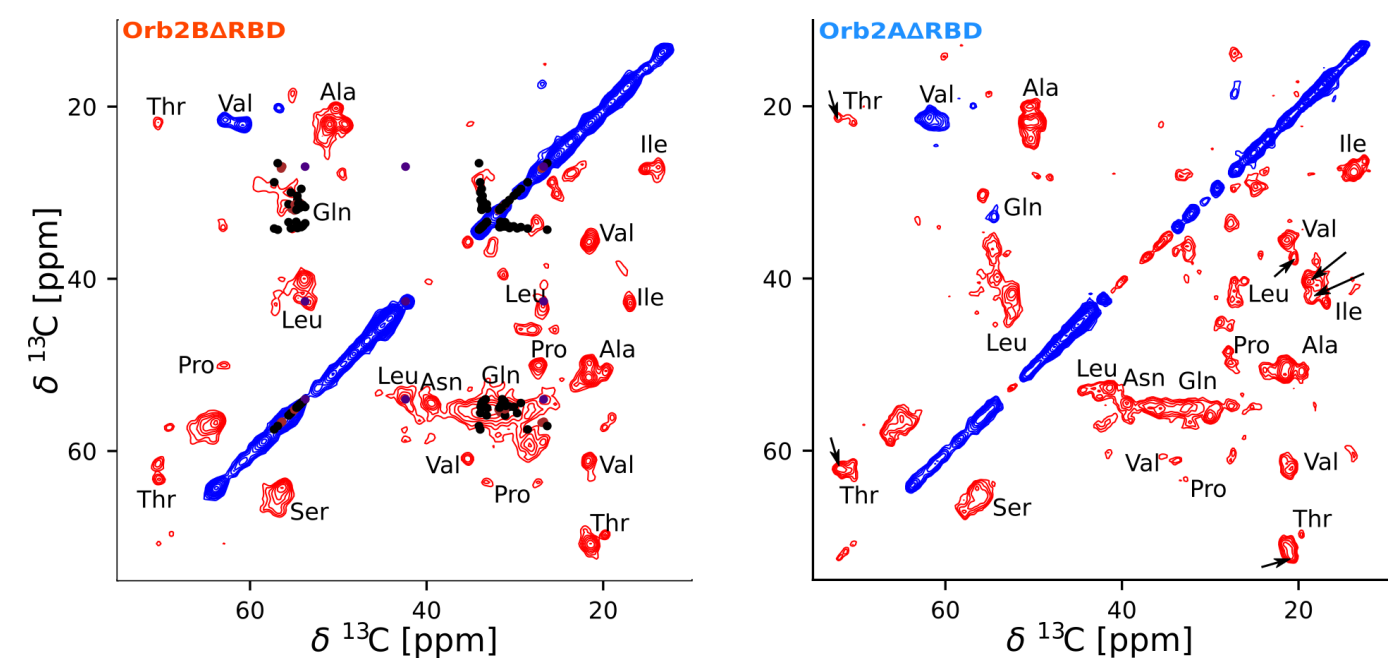

Figure 7: Both Orb2B $\triangle \mathrm{RBD}$ and Orb2A $\triangle \mathrm{RBD}$ fibril spectra show additional immobilized regions beside the $\mathrm{Q} / \mathrm{H}$ rich fibril core. Solid-state NMR $2 \mathrm{D}{ }^{13} \mathrm{C}-{ }^{13} \mathrm{C}$ DREAM spectra of Orb2B $\Delta$ RBD and Orb2A $\Delta$ RBD fibrils. Positive signals are shown in blue, negative signals in red. Amino acids type assignments are indicated. Chemical shifts predicted from the cryo-EM structure (6VPS) using the program Shiftx2 are shown in black, brown, and indigo for Gln, His, and Leu, respectively. The good overlap of these predicted chemical shifts with the experimental data indicates the presence of Q/H-rich Orb2 fibril core. The additional intense and narrow signals of amino acids that are not found in the core (e.g. Val, Pro, Ala, Thr, Asn, Ile), suggest that there are static, well ordered regions other than the $\mathrm{Q} / \mathrm{H}$ rich core in these fibrils. Both spectra are very similar. The few additional cross-peaks detected in the spectra of Orb2A $\triangle \mathrm{RBD}$ fibrils are indicated with arrows. 


\section{Supporting Figures}
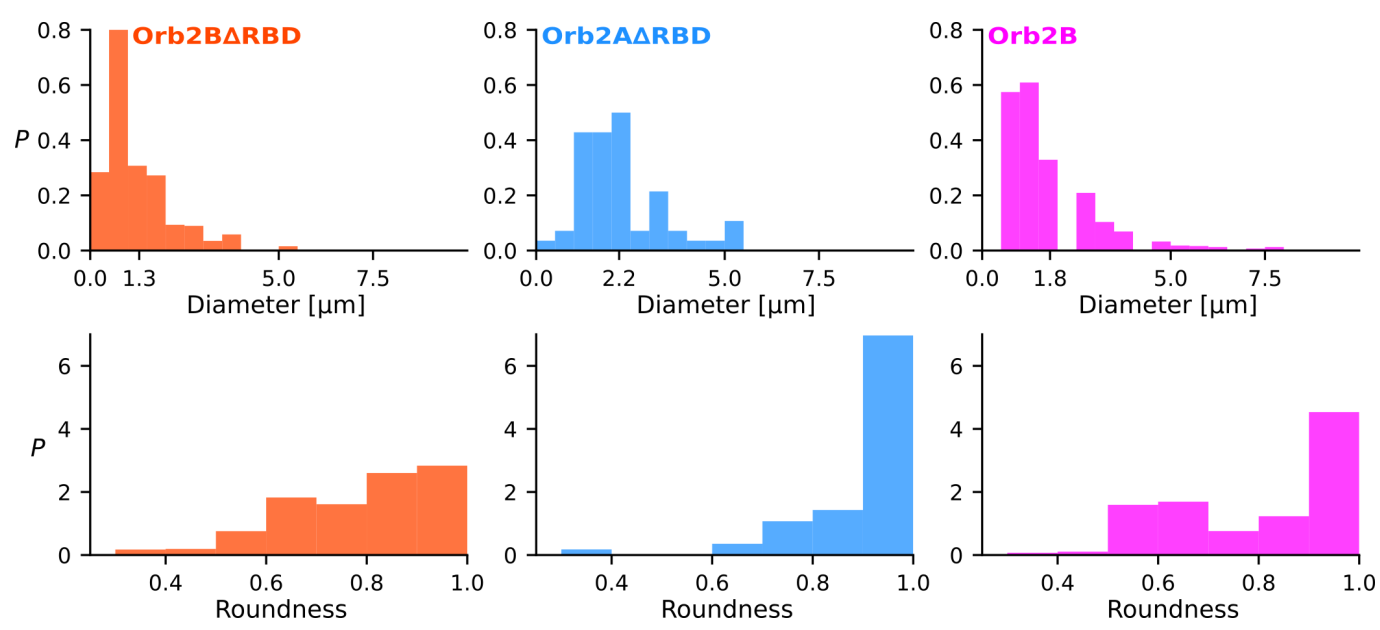

Figure S1: Orb2 droplets are generally between 0 and $5 \mu \mathrm{m}$ in diameter and have a high degree of roundness.

Diameter and roundness of Orb2 droplets were determined using the ImageJ BioVoxxel plugin. Histograms are presented as probability density $P$ and the average diameter is indicated. 

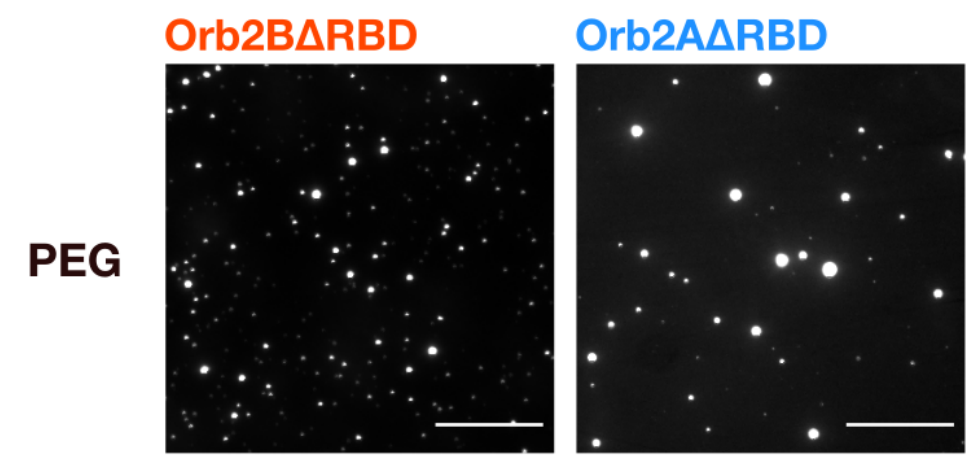

\section{Orb2B}
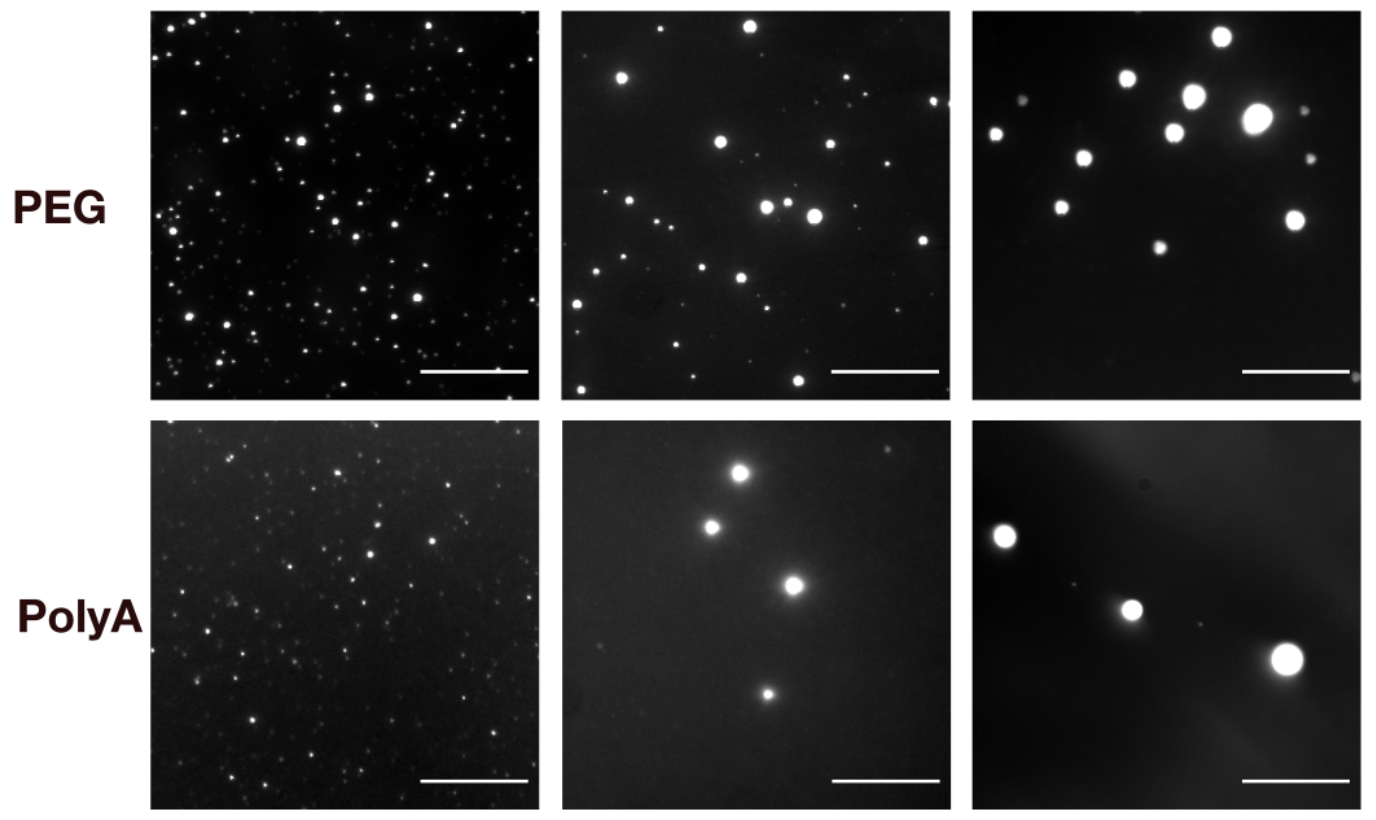

Figure S2: Orb2 also forms droplets in the presence of PEG and RNA. Fluorescence microscopy images of droplets formed by Orb2B $\triangle \mathrm{RBD}$, Orb2A $\triangle \mathrm{RBD}$, and Orb2B immediately after adding 10\% v/v PEG 8000 or PolyA at a 1:10 PolyA:protein $\mathrm{m} / \mathrm{m}$ ratio. Scale bars represent $20 \mu \mathrm{m}$.
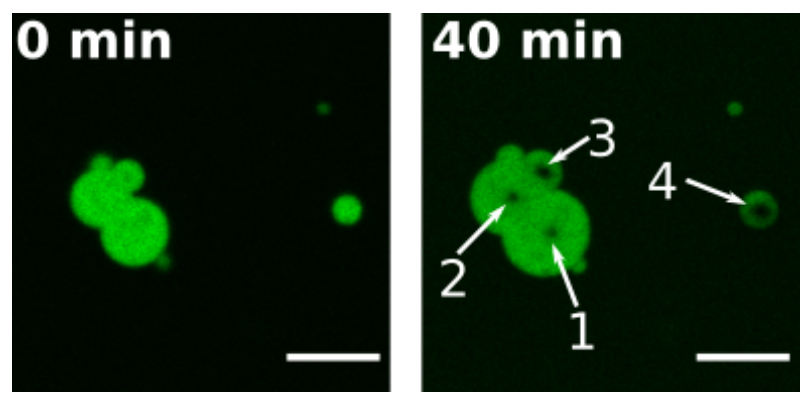

Figure S3: Orb2B shows neither FRAP recovery nor droplet fusion after 40 minutes. Merged Oregon Green 488 labeled Orb2B droplets before (0 min) and after 4 consecutive (indicated with numbers 1-4) 10 minute FRAP experiments (40 min). The fact that neither fluorescence recovery nor droplet fusion events could be observed indicates the relatively static nature of Orb2B inside these droplets. Scale bars represent $5 \mu \mathrm{m}$ 

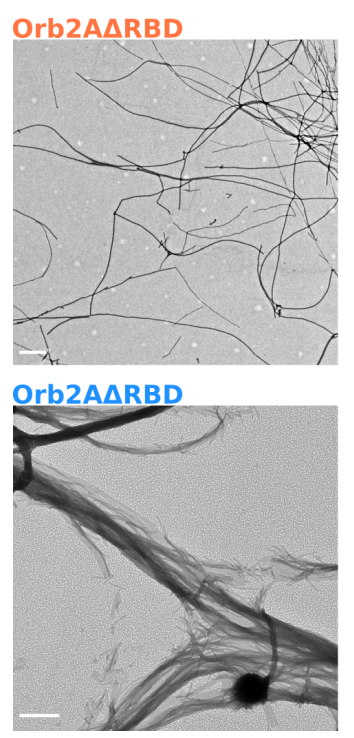
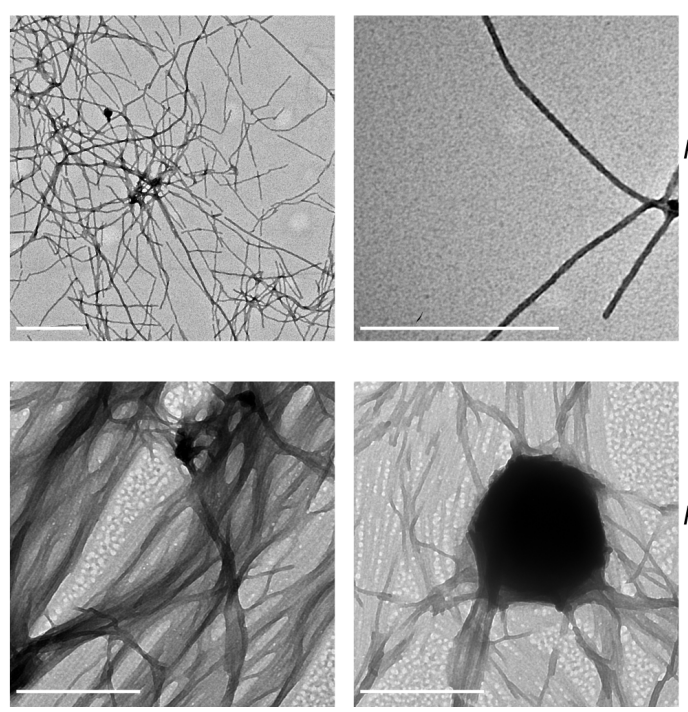
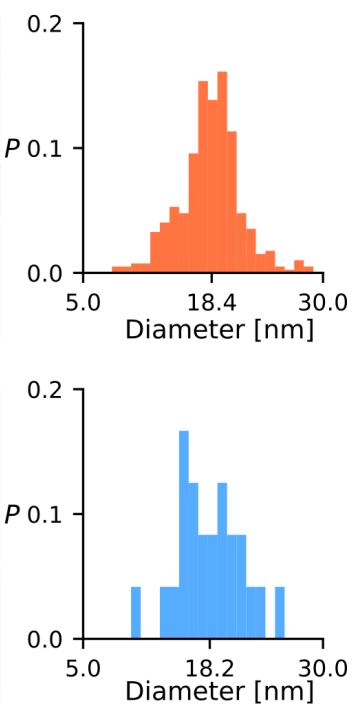

Figure S4: Orb2B $\Delta$ RBD fibrils are relatively unbundeled, whereas Orb2A $\Delta$ RBD fibrils are highly bundeled. Both fibrils have a diameter of about $18 \mathrm{~nm}$ with no visible twist. Negative stained EM images of Orb2B $\Delta$ RBD and Orb2A $\triangle$ RBD fibrils $48 \mathrm{~h}$ after buffer exchange. Scale bars denote $500 \mathrm{~nm}$. Fibril diameters were measured using the ImageJ FibrilJ plugin. Histograms are presented as probability density $P$ and the average diameter is indicated.
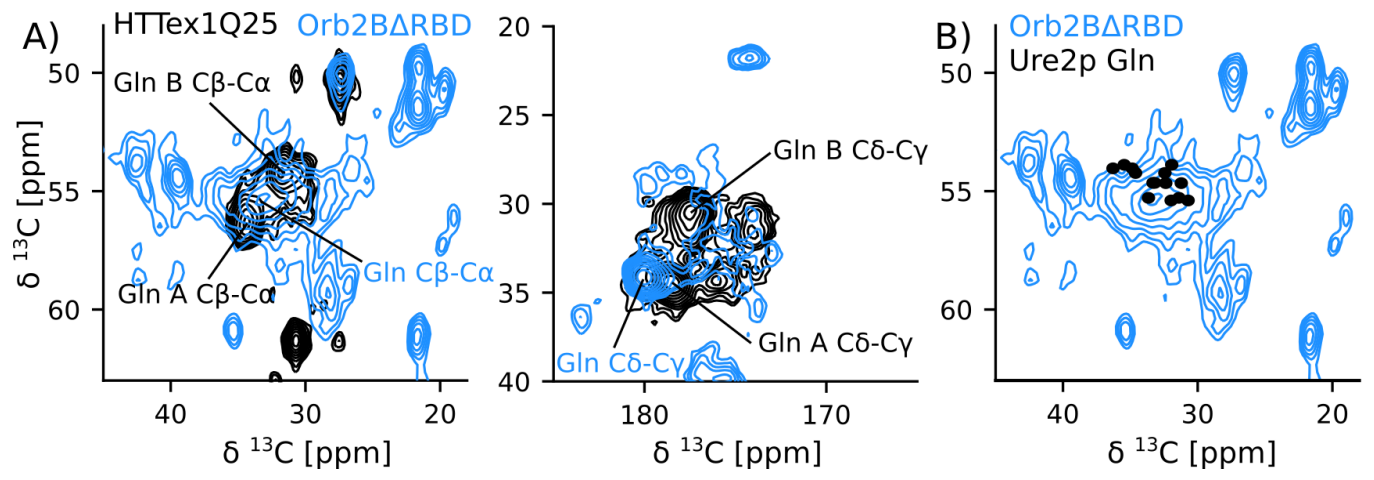

Figure S5: Comparison of Gln peaks in Orb2B $\triangle$ RBD fibril spectra with $\mathrm{HTT}_{\mathrm{ex} 1}$ (Q25) and Sup35p data. A) Overlay of $2 \mathrm{D}^{13} \mathrm{C}-{ }^{13} \mathrm{C}$ spectra of Orb2B $\Delta \mathrm{RBD}$ shown in blue and $\mathrm{HTT}_{\text {ex } 1}$ shown in black. Gln peaks are labeled in the same colors. Where $\mathrm{HTT}_{\mathrm{ex} 1}$ has two major Gln conformations Gln A and Gln B, Orb2B $\Delta \mathrm{RBD}$ has only one. The Gln peak of Orb2B $\triangle \mathrm{RBD}$ does not overlap well with either Gln A and Gln B but its C $\delta$ - $\mathrm{C} \gamma$ peak overlaps with the minor $\mathrm{HTT}_{\mathrm{ex} 1}$ Gln conformation Gln C. The $\mathrm{HTT}_{\mathrm{ex} 1}(\mathrm{Q} 25)$ spectrum was recorded using the 2D DARR experiment at $25 \mathrm{kHz}$ MAS with a mixing time of $50 \mathrm{~ms}$. Orb2B $\Delta$ RBD spectrum shown in left panel is a 2D DREAM recorded at $30 \mathrm{kHz}$ MAS, the right panel shows a $2 \mathrm{D}$ DARR recorded at $25 \mathrm{kHz}$ MAS with a mixing time of $50 \mathrm{~ms}$. B) Spectrum of Orb2B $\triangle$ RBD fibrils with black circles indicating the Gln assignments in the core of Ur2p fibrils (BMRB access code 18407). Although not perfect, the Gln resonances of Sup35p are more similar to Orb2B $\Delta \mathrm{RBD}$ compared to $\mathrm{HTT}_{\text {ex } 1}$. 